\title{
Fnr (EtrA) acts as a fine-tuning regulator of anaerobic metabolism in Shewanella oneidensis MR-1
}

Claribel Cruz-García 1,2,10, Alison E Murray ${ }^{1,11}$, Jorge LM Rodrigues ${ }^{4}$, Jeffrey A Gralnick ${ }^{5}$, Lee Ann McCue ${ }^{6}$, Margaret F Romine ${ }^{6}$, Frank E Löffler ${ }^{7,8,9}$ and James M Tiedje ${ }^{1,2,3^{*}}$

\begin{abstract}
Background: EtrA in Shewanella oneidensis MR-1, a model organism for study of adaptation to varied redox niches, shares $73.6 \%$ and $50.8 \%$ amino acid sequence identity with the oxygen-sensing regulators Fnr in E. coli and Anr in Pseudomonas aeruginosa, respectively; however, its regulatory role of anaerobic metabolism in Shewanella spp. is complex and not well understood.

Results: The expression of the nap genes, nrfA, cymA and $h c p$ was significantly reduced in etrA deletion mutant EtrA7-1; however, limited anaerobic growth and nitrate reduction occurred, suggesting that multiple regulators control nitrate reduction in this strain. Dimethyl sulfoxide (DMSO) and fumarate reductase gene expression was down-regulated at least 2-fold in the mutant, which, showed lower or no reduction of these electron acceptors when compared to the wild type, suggesting both respiratory pathways are under EtrA control. Transcript analysis further suggested a role of EtrA in prophage activation and down-regulation of genes implicated in aerobic metabolism.
\end{abstract}

Conclusion: In contrast to previous studies that attributed a minor regulatory role to EtrA in Shewanella spp., this study demonstrates that EtrA acts as a global transcriptional regulator and, in conjunction with other regulators, fine-tunes the expression of genes involved in anaerobic metabolism in S. oneidensis strain MR-1. Transcriptomic and sequence analyses of the genes differentially expressed showed that those mostly affected by the mutation belonged to the "Energy metabolism" category, while stress-related genes were indirectly regulated in the mutant possibly as a result of a secondary perturbation (e.g. oxidative stress, starvation). We also conclude based on sequence, physiological and expression analyses that this regulator is more appropriately termed Fnr and recommend this descriptor be used in future publications.

\section{Background}

Due to its respiratory versatility, Shewanella oneidensis strain MR-1 serves as a model organism for studying the regulation of aerobic and anaerobic growth [1-3]. In contrast to Escherichia coli, the regulatory systems that control transcription of genes responsible for different respiratory processes are poorly understood in environmentally relevant Shewanella spp. [4-7]. In E. coli, the transition from aerobic to anaerobic metabolism is primarily regulated by Fnr (fumarate and nitrate reduction

\footnotetext{
* Correspondence: tiedjej@msu.edu

'Center for Microbial Ecology, Michigan State University, East Lansing, Michigan 48824-1325, USA

Full list of author information is available at the end of the article
}

regulator) and by the two-component regulatory system ArcAB (aerobic respiration control) [8-11]. A gene expression study in E. coli $\mathrm{K} 12$ indicated that one-third of its 4,290 genes were differentially expressed during aerobic versus anaerobic growth [12]. Among the differentially expressed genes, 712 (49\%) genes were directly or indirectly affected by Fnr. Fnr possesses a $[4 \mathrm{Fe}-4 \mathrm{~S}]^{2+}$ cluster that acts as an oxygen sensory domain [13]. Fnr in its active dimeric form binds to target DNA sequences inducing or repressing transcription $[14,15]$. Under aerobic conditions, or when oxygen levels increase, an $\mathrm{Fe}^{2+}$ atom in the $[4 \mathrm{Fe}-4 \mathrm{~S}]^{2+}$ cluster is oxidized resulting in the formation of a $[2 \mathrm{Fe}-2 \mathrm{~S}]^{2+}$ cluster via a $[3 \mathrm{Fe}-4 \mathrm{~S}]^{1+}$ intermediate. This oxidation causes a

\section{Ciomed Central}


conformation change in Fnr, thus altering its affinity to DNA and regulatory control of transcription $[14,15]$.

Studies with strain MR-1 mutants have identified three important regulators of anaerobic metabolism: EtrA (electron transport regulator protein), ArcA and CRP (cyclic ĀMP receptor protein) [4,5,16-19]. Sequence alignment of the protein encoded by etrA reveal that the four cysteine residues that form the [4Fe$4 \mathrm{~S}]^{2+}$ cluster in Fnr are conserved in EtrA [16]. In a gene replacement study, etrA of strain MR-1 restored wild type physiology of an E. coli fnr deletion mutant [16]. EtrA shares $73.6 \%$ and $50.8 \%$ of amino acid sequence identity with Fnr in E. coli and Anr (arginine deaminase and nitrate reductase anaerobic regulator) in Pseudomonas aeruginosa, respectively. This high degree of similarity suggests that EtrA has a regulatory function in MR-1, possibly by sensing oxygen. Despite the lack of physiological evidence to support a regulatory role of EtrA in the anaerobic metabolism of strain MR-1 [7], a gene expression study using a partial microarray (691 ORFs) of the strain MR-1's genome suggested involvement of EtrA in the regulation of the transcription of genes associated with aerobic and anaerobic metabolism [6]. Growth experiments with an etrA deletion mutant in S. oneidensis strain DSP10 (a spontaneous rifampicin resistant mutant of MR-1) implicated EtrA in the regulation of genes related to aerobic and anaerobic metabolism, similar to what has been observed for Fnr in E. coli $[12,20]$. Unfortunately, the implications of these findings cannot be interpreted unambiguously since the rifampicin resistance of strain DSP10 influences electron transport [21].

To examine the regulatory role of EtrA in strain MR-1 in more detail, we generated an etrA knockout mutant EtrA7-1 in a wild type background. Growth and phenotypic characterization of this mutant combined with a whole genome transcriptome analysis confirms that EtrA regulates nitrate and fumarate reduction, plus provides experimental evidence for its positive regulatory role in DMSO reduction. Our genome-wide expression analysis shows differential expression of 612 genes for which sequence analysis recognized a EtrA motif for 72 of the operons encoding 118 genes, suggesting that their regulation is via direct interaction of EtrA with its promoters. Most of these genes are associated with metabolic functions.

\section{Results}

\section{Genotypic and phenotypic characterization of a $\triangle e t r A::$} loxP mutant

The growth of the etrA knockout mutant EtrA7-1 with nitrate was significantly impaired as cultures reached a maximum $\mathrm{OD}_{600}$ of 0.02 , at least 5-fold lower than the wild type strain (Figure 1). In addition, the doubling time for the mutant under these conditions was approximately

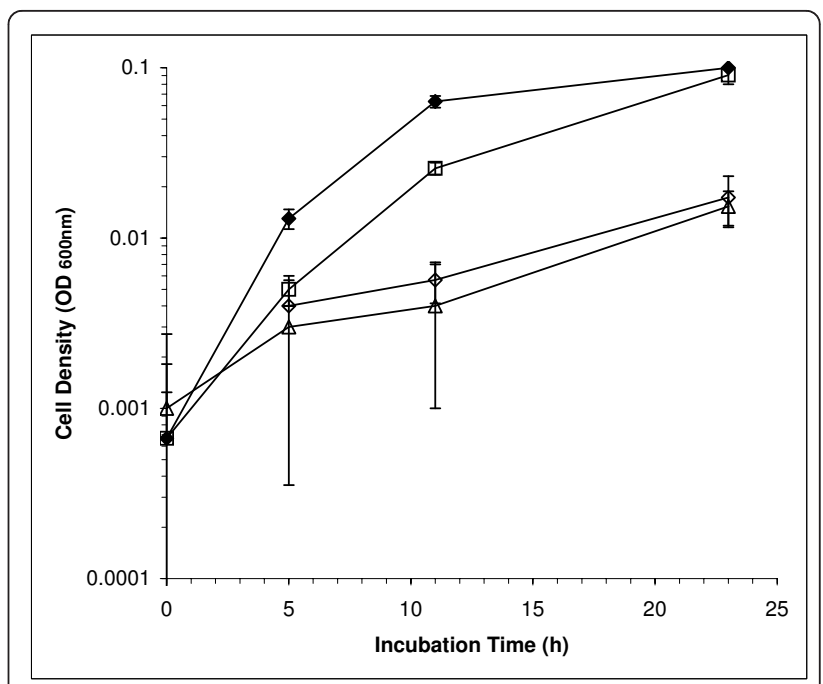

Figure 1 Anaerobic growth of EtrA7-1 and the wild type strains on lactate and nitrate. Wild type strain (closed diamonds), EtrA7-1 complement strain (open squares), EtrA7-1 (open diamonds) and EtrA7-1 harboring PCM62 (open triangles) served as a negative control. Data are means and SD from three independent cultures.

$10 \mathrm{~h}$ compared to a doubling time of $2 \mathrm{~h}$ for the wild type. Plasmid pCCG03 carrying etrA, but not the parental pCM62 vector lacking etrA, restored near wild type growth to the EtrA7-1 mutant, which confirms that the observed phenotype was attributable to the deletion of etrA. After $10 \mathrm{~h}$ of incubation, nitrate was reduced in wild type and complemented EtrA7-1 cultures though less nitrate was reduced in the latter consistent with its slightly slower growth (Figure 2). After $23 \mathrm{~h}$, both the wild type and EtrA7-1 complement had completely converted nitrate and nitrite to ammonia, while nitrite was the major product in cultures of the EtrA7-1 mutant and the control strain harboring pCM62 (Figure 2).

Anaerobic cultures of the mutant and the wild type strain were analyzed for the reduction of different electron acceptors with lactate as the electron donor. No growth of the EtrA7-1 mutant was observed with fumarate as electron acceptor whereas the wild type strain reached an $\mathrm{OD}_{600}$ of $0.053 \pm 0.005$. Limited growth (approximately $50 \%$ lower $\mathrm{OD}_{600}$ compared with the wild type cultures) was observed in mutant cultures amended with trimethylamine $\mathrm{N}$-oxide (TMAO) or thiosulfate (data not shown). No OD increases with the mutant and the wild type were measured with DMSO provided as electron acceptor at 2 and $10 \mathrm{mM}$; however, HPLC analyses of cultures with $2 \mathrm{mM}$ DMSO revealed that DMSO was completely consumed in wild type cultures, whereas no DMSO consumption was evident in the mutant cultures (Figure 3). No changes in DMSO concentrations were observed in cultures with $10 \mathrm{mM}$ DMSO. No significant differences in $\mathrm{Fe}(\mathrm{III}), \mathrm{Mn}(\mathrm{IV})$ and 
A.

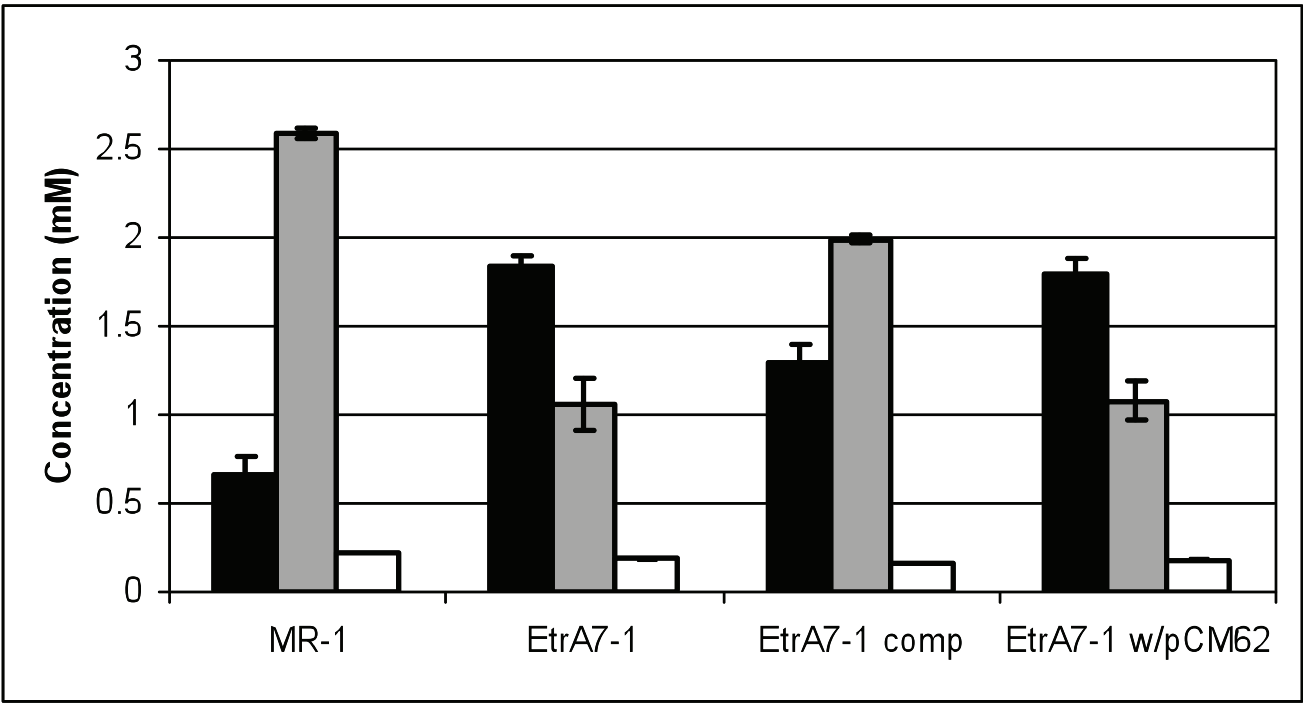

B.

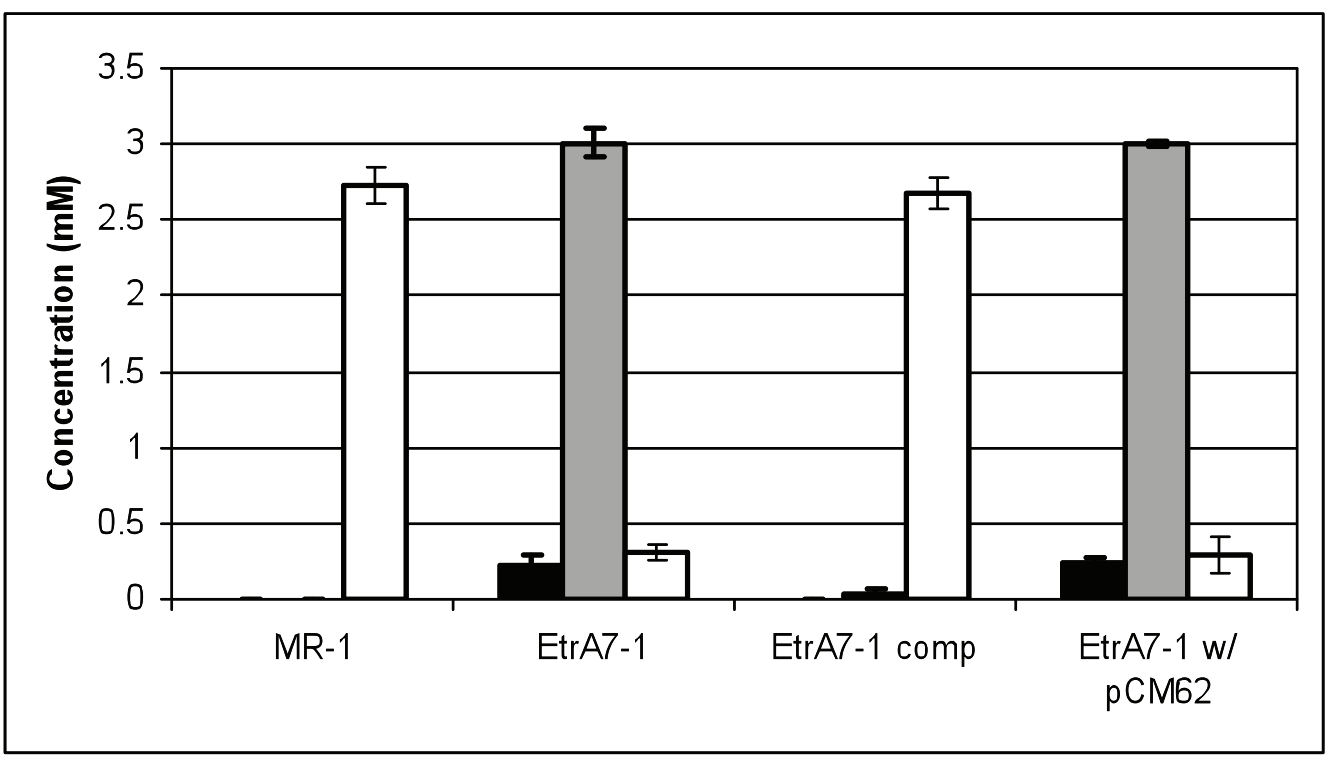

Figure 2 Nitrate consumption and products formed during growth of the EtrA7-1 and wild type strains in Figure 1. Samples were collected after $10 \mathrm{~h}$ (panel A) and $23 \mathrm{~h}$ (panel B) and analyzed for nitrate (black bar), nitrite (gray bar) and ammonium (white bar). Data are means and SD from three independent cultures.

sulfite reduction rates were observed between the wild type and the EtrA7-1 deletion mutant (Figure 3). Anaerobic cultures of the mutant and the wild type strains grown with pyruvate instead of lactate as electron donor showed similar results, i.e., the mutant showed limited or no growth with nitrate, fumarate and DMSO provided as electron acceptors compared to the wild type (Figure 4). Similar to the lactate-amended cultures, the rates of nitrate, fumarate and DMSO reduction in wild type cultures exceeded those measured in cultures of the mutant strain (Table 1). Resting cell assays corroborated these findings and nitrate reduction and ammonium production occurred at higher rates in assays with wild type cells. Complete stoichiometric conversion to ammonium also occurred in the assays with mutant cells, although lower rates and a 3 -fold longer incubation were required for complete reduction (i.e., $24 \mathrm{~h}$ for the EtrA7-1 versus $8 \mathrm{~h}$ for the wild type) (Figure 5). 


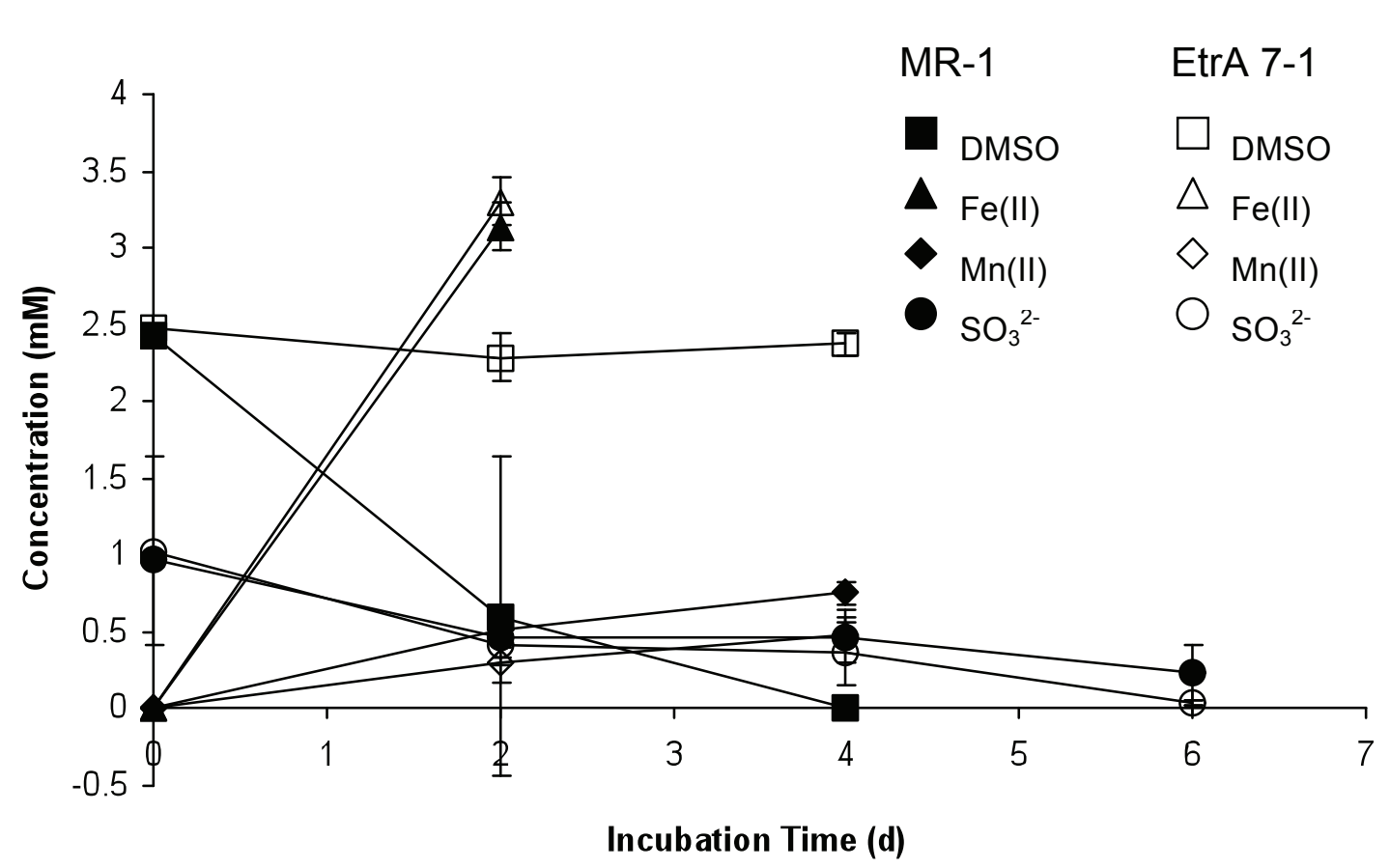

Figure 3 Substrate consumption and intermediate production in anaerobic cultures of the wild type (closed symbols) and EtrA7-1 (open symbols) mutant strains grown with lactate and different electron acceptors. DMSO consumption, squares; Fe(II) production, triangles; Mn(II) production, diamonds and sulfite consumption, circles. Data are means and SD from three independent cultures.

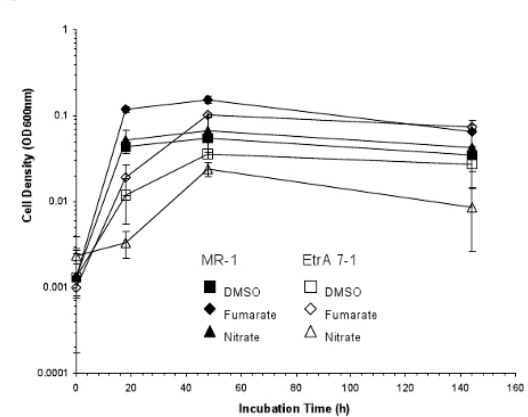

B.

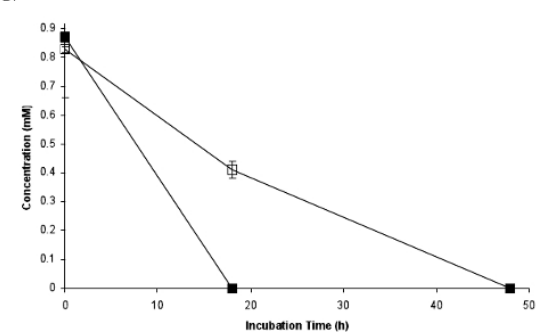

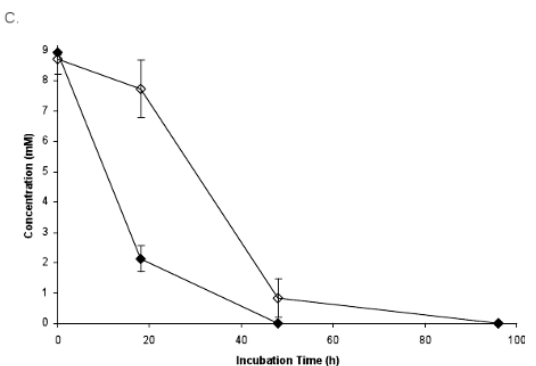

D.

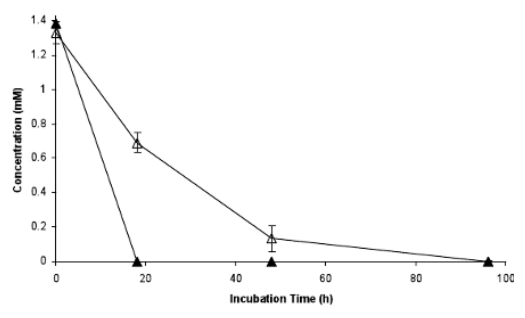

Figure 4 Growth of the wild type (closed symbols) and Etra7-1 (open symbols) strains with pyruvate and the indicated electron acceptor. (Panel A) DMSO consumption - squares (Panel B), fumarate consumption - diamonds (Panel C) and nitrate comsumption - triangles (Panel D). Data are means and SD from three independent cultures. 
Table 1 Comparison of reduction rates of several electron acceptors with pyruvate as electron donor by $S$. oneidensis MR-1 wild type strain and etrA knockout strain EtrA7-1

\begin{tabular}{|c|c|c|}
\hline Electron acceptor & Wild type $\left(\mu \mathrm{M} \min ^{-1}\right)$ & ETRA7-1 $\left(\mu \mathrm{M} \mathrm{min}^{-1}\right)$ \\
\hline Nitrate & $1.2 \pm 0.1$ & $0.3 \pm 0.01$ \\
\hline Fumarate & $6.4 \pm 0.6$ & $3.8 \pm 0.2$ \\
\hline DMSO & $0.8 \pm 0.2$ & $0.4 \pm 0.1$ \\
\hline
\end{tabular}

Data are means \pm the standard deviation from three independent cultures.

\section{Effects of etrA deletion on transcription}

The global transcriptome profile of mutant strain EtrA71 grown anaerobically with nitrate as the sole electron acceptor was compared to that of the wild type under the same growth conditions. A complete list of all the genes differentially expressed two-fold or higher is provided as supplemental information (Additional file 1). Out of 612 differentially transcribed genes in the EtrA71 mutant relative to the wild type, 289 were up-regulated and 323 were down-regulated. The differentially transcribed genes were classified in 19 functional "TIGR Role" categories (Additional file 2) based on the MR-1 genome annotation (GenBank accession number AE014299) [22]. Genes with unknown functions represented the largest category of up-regulated (14.8\%) and the second most common category of down-regulated genes (17.3\%). Genes associated with energy metabolism were the largest category (17.6\%) of down-regulated genes (Additional file 2). Among the up-regulated genes, the "Protein synthesis" category ranked second (12.5\%) and the "Other categories" ranked third (11.4\%). This latter category included phage-, transposase- and plasmid-related genes. The "Energy metabolism" category represented $9.7 \%$, ranking fourth.

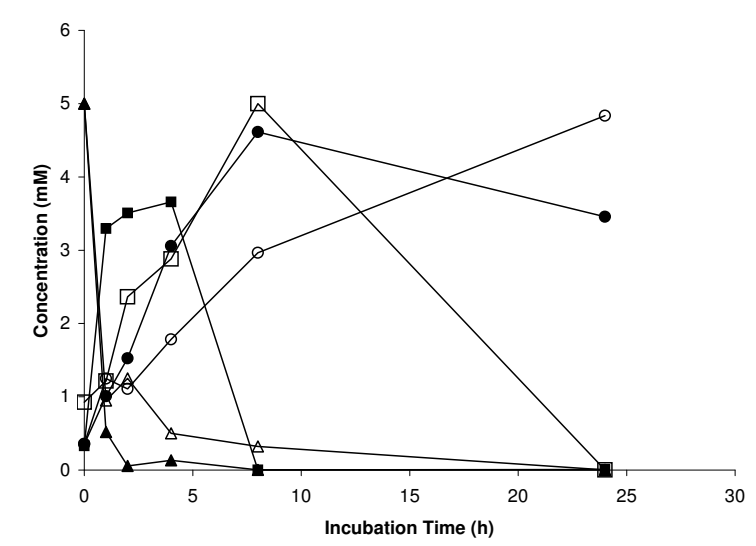

Figure 5 Nitrate reduction in resting cell assays with the wild type (closed symbols) and the ETRA7-1 (open symbols) mutant strains. Nitrate - triangles, nitrite - squares and ammonium - circles. Nitrate measurements in killed controls did not change, while nitrite and ammonium were not detected (data not shown).
Identification of putative EtrA binding sites

The promoters of the differentially expressed genes were examined for putative EtrA binding sites in order to identify those genes that were likely directly regulated by EtrA from the many genes whose expression changes were most likely due to secondary effects. For example, the up-regulation of phage-related genes is likely a response to stress, and not a direct result of the etrA deletion. Putative EtrA binding sites were identified for those genes that showed at least 2.5 fold change in the EtrA7-1 mutant relative to the wild type by extracting the upstream intergenic sequences and applying the Gibbs centroid sampler to identify a putative binding site motif. A motif was identified (Additional file 3) that displays similarities to the E. coli Fnr and Crp binding sites motifs; this motif was present upstream of 44 operons that encode a total of 78 genes. The largest proportion of these genes is in the "Energy metabolism" category (Table 2 and 3, Additional file 2). Binding sites were detected upstream of an additional 28 operons when the detected motif (Additional file 3) was used to scan the upstream intergenic regions of all genes listed in Additional file 1.

\section{Regulatory role of EtrA in energy metabolism}

Since the "Energy metabolism" category contained the largest group of genes responsive to EtrA, these genes were analyzed in more detail. Up-regulated genes (Table 2) in this group included genes encoding a cytochrome $c$ oxidase (ccoPQN [SO2361-2362, SO2364]), proteins involved in gluconeogenesis such as PckA (SO0162), and nqrABCDEF-2 genes (SO1103-1108) encoding NADH:ubiquinone oxidoreductases. From this group, only the nqr gene clusters had a putative EtrA binding site.

While the $n q r-2$ gene cluster was up-regulated in the etrA knockout mutant, the $n q r-1$ gene cluster (SO09030907) was down-regulated. $\mathrm{Nqr}$ is a $\mathrm{Na}^{+}$pump that during respiration generates a sodium motive force to mediate solute transport, flagellar motility and ATP synthesis [23]. Both nqr gene clusters had putative EtrA binding sites. The microarray data indicated that EtrA affects the transcription pattern of these genes differently. Similarly, the etrA deletion had a distinct effect on the expression of the $f d h$ gene clusters encoding a formate dehydrogenase. The $f d h-1$ genes (SO4508-4511) were up-regulated whereas the $f d h-2$ gene cluster (SO4512-4515) was down-regulated. An EtrA binding site was only identified for the $f d h-2$ cluster and not for the $f d h-1$ cluster, indicating EtrA affects both clusters differently.

Other up-regulated genes in the "Energy metabolism" category included the succinate dehydrogenase gene $s d h C$ (SO1927), the succinyl-CoA synthase operon 
sucABCD (SO1930-1933), the butyryl-CoA:acetate CoAtransferase and the acetyl CoA-synthase genes (SO18911892).

Down-regulated genes in the "Energy metabolism" category (Table 3), which were predicted for direct regulation by EtrA, included genes involved in anaerobic metabolism, especially in nitrate respiration like the napBHGAD operon (SO0845-0849, strongly repressed with all subunit genes except napD with ratios $\leq 0.18$ ), and the $n r f A$ (SO3980) genes. cymA (SO4591; ratio 0.39 ), the prismane protein $h c p$ gene (SO1363), and neighboring protein $h c r$ gene (SO1364), both of which were strongly repressed (ratios $\leq 0.13$ ) and have been associated with the nitrate reduction pathway [24-27], did not show evidence of EtrA binding sites. Also indirectly down-regulated were the fumarate reductase genes frdAB (SO0398-0399) and $f c c A$ (SO0970), the ackA and the pta (SO2915-16) genes involved in acetate production and the $p p c$ (SO0274) gene encoding an acetate phosphoenol pyruvate carboxylase. The hyaCBA (SO2097-2099) genes encoding a quinone-reactive $\mathrm{Ni} / \mathrm{Fe}$ hydrogenase were highly indirectly repressed (ratio $\leq$ 0.11 ). Among the genes identified as directly down-regulated are all the genes in the operon that encodes the anaerobic DMSO reductase (dms $A B)$ (SO1428-32), the $c y d A B$ genes (SO3285-3286) encoding a cytochrome $d$ oxidase complex, as well as genes involved in metabolism of organic compounds such as the pflAB (SO29122913).

Other down-regulated genes grouped in different categories included genes encoding $\mathrm{ABC}$ transporters (cydCD [SO3779-3780], SO4446-4448), TonB-dependent receptors (nosA [SO0630]), and L-lactate permease (lldP [SO0827]) and a putative lactate permease (SO1522). The only gene directly down-regulated from this later group is $l l d P$ (SO0827), for which an EtrA binding site

Table 2 Genes induced in the "Energy Metabolism" category in anaerobic cultures of EtrA7-1 relative to the wild type (reference strain)

\begin{tabular}{|c|c|c|c|c|}
\hline $\begin{array}{l}\text { Gene } \\
\text { ID }\end{array}$ & $\begin{array}{l}\text { Gene } \\
\text { name }\end{array}$ & $\begin{array}{c}\text { Relative } \\
\text { expression }^{\mathrm{a}}\end{array}$ & Predicted EtrA binding sites ${ }^{c}$ & COG Annotation \\
\hline SO0162 & $p c k A$ & $2.21( \pm 0.48)^{b}$ & TGTGAGCTGGATCATT & phosphoenolpyruvate carboxykinase (ATP) \\
\hline SO0747 & fpr & $2.17( \pm 1.01)$ & & ferredoxin-NADP reductase \\
\hline SO1103 & $n a r A-2$ & $2.25( \pm 0.54)$ & $\begin{array}{l}\text { TCTGCGCTAGCTCAAT } \\
\text { CGTGATTGCGATCGCA }\end{array}$ & NADH:ubiquinone oxidoreductase, Na translocating, alpha subunit \\
\hline SO1104 & $n a r B-2$ & $2.70( \pm 1.01)$ & $\downarrow$ & $\begin{array}{l}\text { NADH:ubiquinone oxidoreductase, Na translocating, hydrophobic } \\
\text { membrane protein NqrB }\end{array}$ \\
\hline SO1105 & narC-2 & $3.15( \pm .080)$ & $\downarrow$ & NADH:ubiquinone oxidoreductase, Na translocating, gamma subunit \\
\hline SO1106 & nqrD-2 & $4.65( \pm 2.07)$ & $\downarrow$ & $\begin{array}{l}\text { NADH:ubiquinone oxidoreductase, Na translocating, hydrophobic } \\
\text { membrane protein NarD }\end{array}$ \\
\hline SO1107 & narE-2 & $3.63( \pm 1.61)$ & $\downarrow$ & $\begin{array}{l}\text { NADH:ubiquinone oxidoreductase, Na translocating, hydrophobic } \\
\text { membrane protein NqrE }\end{array}$ \\
\hline SO1108 & $n a r F-2$ & $4.21( \pm 2.05)$ & $\downarrow$ & NADH:ubiquinone oxidoreductase, Na translocating, beta subunit \\
\hline SO1891 & $S C O B$ & $3.77( \pm 1.80)$ & & Acetyl-CoA:acetoacetate CoA transferase, alpha subunit AtoA \\
\hline SO1892 & SCOA & $3.21( \pm 2.14)$ & & acetate CoA-transferase, beta subunit AtoD \\
\hline SO1927 & $\operatorname{sdhC}$ & $2.47( \pm 1.26)$ & & succinate dehydrogenase, cytochrome b556 subunit \\
\hline SO1930 & SUCA & $3.02( \pm 1.22)$ & & 2-oxoglutarate dehydrogenase, E1 component \\
\hline SO1931 & $\operatorname{sucB}$ & $3.60( \pm 1.58)$ & & $\begin{array}{l}\text { 2-oxoglutarate dehydrogenase, E2 component, dihydrolipoamide } \\
\text { succinyltransferase }\end{array}$ \\
\hline SO1932 & succ & $3.29( \pm 0.98)$ & & succinyl-CoA synthase, beta subunit \\
\hline SO1933 & sucD & $3.28( \pm 1.24)$ & & succinyl-CoA synthase, alpha subunit \\
\hline SO2361 & CCOP & $2.30( \pm 0.92)$ & $\uparrow$ & cytochrome c oxidase, cbb3-type, subunit III \\
\hline SO2362 & $\operatorname{cco}$ & $3.44( \pm 1.16)$ & $\uparrow$ & cytochrome c oxidase, cbb3-type, CcoQ subunit \\
\hline SO2364 & $\mathrm{cCON}$ & $2.76( \pm 1.07)$ & $\begin{array}{l}\text { CTTGAGCCATGTCAAA } \\
\text { GTTGATCTAGATCAAT }\end{array}$ & cytochrome c oxidase, cbb3-type, subunit I \\
\hline SO4509 & $f d h A-1$ & $2.33( \pm 0.56)$ & & formate dehydrogenase, alpha subunit \\
\hline SO4510 & $f d h B-1$ & $4.03( \pm 1.57)$ & & formate dehydrogenase, iron-sulfur subunit \\
\hline SO4511 & $f d h C-1$ & $2.53( \pm 0.31)$ & & formate dehydrogenase, $C$ subunit, putative \\
\hline
\end{tabular}

\footnotetext{
a The relative expression is presented as the ratio of the dye intensity of the anaerobic cultures with $2 \mathrm{mM} \mathrm{KNO}_{3}$ of EtrA7-1 to that of MR-1 (reference).

$\mathrm{b}$ The standard deviation was calculated from six data points, which included three independent biological samples and two technical samples for each biological sample.

c The arrows indicate that the gene is regulated by the binding site that follows. The direction of the arrow indicates the location of the gene. An arrow pointing down indicates the gene or operon is in the plus or sense strand and the arrow pointing up indicates the gene or operon is in the minus or anti-sense strand.
} 
Table 3 Genes repressed in the "Energy metabolism" category in anaerobic cultures of EtrA7-1 grown on lactate and nitrate relative to the wild type (reference strain)

\begin{tabular}{|c|c|c|c|c|}
\hline $\begin{array}{l}\text { Gene } \\
\text { ID }\end{array}$ & $\begin{array}{l}\text { Gene } \\
\text { name }\end{array}$ & $\begin{array}{l}\text { Relative } \\
\text { expression }^{\mathrm{a}}\end{array}$ & Predicted EtrA binding sites ${ }^{c}$ & COG Annotation \\
\hline SO0274 & $p p c$ & $0.48( \pm 0.19)$ & & phosphoenolpyruvate carboxylase \\
\hline SO0398 & frdA & $0.30( \pm 0.16)^{b}$ & & fumarate reductase flavoprotein subunit \\
\hline SO0399 & $\operatorname{frdB}$ & $0.39( \pm 0.06)$ & & fumarate reductase iron-sulfur protein \\
\hline SO0845 & napB & $0.15( \pm 0.04)$ & & cytochrome c-type protein NapB \\
\hline SO0846 & napH & $0.18( \pm 0.11)$ & & iron-sulfur cluster-binding protein napH \\
\hline SO0847 & napG & $0.14( \pm 0.07)$ & & iron-sulfur cluster-binding protein NapG \\
\hline SO0848 & napA & $0.18( \pm 0.13)$ & $\uparrow$ & periplasmic nitrate reductase \\
\hline SO0849 & napD & $0.30( \pm 0.04)$ & GTCGATCGGGATCAAA CGTGATCTAACTCTCA & napD protein \\
\hline SO0903 & $n q r B-1$ & $0.34( \pm 0.15)$ & TाTGCTGTAAAGCAAA TGTGCATGGAATCGCC & $\begin{array}{l}\text { NADH:ubiquinone oxidoreductase, Na translocating, } \\
\text { hydrophobic membrane protein NqrB }\end{array}$ \\
\hline SO0904 & narC-1 & $0.28( \pm 0.09)$ & $\downarrow$ & $\begin{array}{l}\text { NADH:ubiquinone oxidoreductase, Na translocating, gamma } \\
\text { subunit }\end{array}$ \\
\hline SO0905 & narD-1 & $0.27( \pm 0.14)$ & $\downarrow$ & $\begin{array}{l}\text { NADH:ubiquinone oxidoreductase, Na translocating, } \\
\text { hydrophobic membrane protein NarD }\end{array}$ \\
\hline SO0906 & narE-1 & $0.23( \pm 0.07)$ & $\downarrow$ & $\begin{array}{l}\text { NADH:ubiquinone oxidoreductase, Na translocating, } \\
\text { hydrophobic membrane protein NarE }\end{array}$ \\
\hline SO0907 & nqrF-1 & $0.23( \pm 0.08)$ & & $\begin{array}{l}\text { NADH:ubiquinone oxidoreductase, Na translocating, beta } \\
\text { subunit }\end{array}$ \\
\hline SO0970 & $f C C A$ & $0.31( \pm 0.17)$ & & Periplasmic fumarate reductase, FccA \\
\hline SO1018 & nuoE & $0.44( \pm 0.17)$ & & NADH dehydrogenase I, E subunit \\
\hline SO1019 & nuoCD & $0.35( \pm 0.13)$ & & NADH dehydrogenase I, C/D subunits \\
\hline SO1020 & nuoB & $0.40( \pm 0.10)$ & & NADH dehydrogenase I, B subunit \\
\hline SO1363 & hcp & $0.13( \pm 0.08)$ & & prismane protein \\
\hline SO1364 & her & $0.12( \pm 0.07)$ & & iron-sulfur cluster-binding protein \\
\hline SO1429 & $d m s A-1$ & $0.43( \pm 0.09)$ & TGTGATACAATTCAAA & anaerobic dimethyl sulfoxide reductase, A subunit \\
\hline SO1430 & $d m s B-1$ & $0.29( \pm 0.04)$ & $\downarrow$ & anaerobic dimethyl sulfoxide reductase, B subunit \\
\hline SO1490 & $a d h B$ & $0.28( \pm 0.12)$ & TGTGATCTAGATCGGT TTGGAACTAGATAACT & alcohol dehydrogenase II \\
\hline SO1776 & $m t r B$ & $0.22( \pm 0.04)$ & & outer membrane protein precursor MtrB \\
\hline SO1777 & $m t r A$ & $0.25( \pm 0.06)$ & & decaheme cytochrome c MtrA \\
\hline SO1778 & $m t r C$ & $0.30( \pm 0.09)$ & & decaheme cytochrome c MtrC \\
\hline SO1779 & omcA & $0.30( \pm 0.05)$ & $\begin{array}{c}\text { GTGGAATTAGATCCCA TGTGATTGAGATCTGA } \\
\text { TTTGAGGTAGATAACA }\end{array}$ & decaheme cytochrome c \\
\hline SO2097 & hyac & $0.07( \pm 0.04)$ & & quinone-reactive Ni/Fe hydrogenase, cytochrome b subunit \\
\hline SO2098 & hyaB & $0.11( \pm 0.10)$ & & quinone-reactive Ni/Fe hydrogenase, large subunit \\
\hline SO2099 & hyaA & $0.07( \pm 0.11)$ & & quinone-reactive Ni/Fe hydrogenase, small subunit precursor \\
\hline SO2136 & adhE & $0.40( \pm 0.10)$ & & aldehyde-alcohol dehydrogenase \\
\hline SO2912 & $p f \mid B$ & $0.18( \pm 0.11)$ & TITGAGCTGAAACAAA & formate acetyltransferase \\
\hline SO2913 & $p f l A$ & $0.20( \pm 0.13)$ & & pyruvate formate-lyase 1 activating enzyme \\
\hline SO2915 & $a c k A$ & $0.23( \pm 0.16)$ & & acetate kinase \\
\hline SO2916 & pta & $0.23( \pm 0.14)$ & & phosphate acetyltransferase \\
\hline SO3144 & etfA & $0.36( \pm 0.13)$ & & electron transfer flavoprotein, alpha subunit \\
\hline SO3285 & $c y d B$ & $0.21( \pm 0.06)$ & $\uparrow$ & cytochrome d ubiquinol oxidase, subunit II \\
\hline SO3286 & $\operatorname{cyd} d A$ & $0.22( \pm 0.10)$ & TTTGATTCAAATCAAT & cytochrome d ubiquinol oxidase, subunit I \\
\hline SO3980 & nrfa & $0.18( \pm 0.06)$ & TITGCGCTAGATCAAA & cytochrome c552 nitrite reductase \\
\hline SO4513 & $f d h A-2$ & $0.06( \pm 0.02)$ & ACTGTTCTAGATCAAA & formate dehydrogenase, alpha subunit \\
\hline SO4515 & $f d h C-2$ & $0.07( \pm 0.01)$ & & formate dehydrogenase, $C$ subunit, putative \\
\hline SO4591 & cymA & $0.39( \pm 0.27)$ & & tetraheme cytochrome $\mathrm{c}$ \\
\hline
\end{tabular}

${ }^{a}$ The relative expression is presented as the ratio of the dye intensity of the anaerobic cultures with $2 \mathrm{mM} \mathrm{KNO}_{3}$ of EtrA7-1 to that of MR-1 (reference).

${ }^{\mathrm{b}}$ The standard deviation was calculated from six data points, which included three independent biological samples and two technical samples for each biological sample.

c The arrows indicate that the gene is regulated by the binding site that follows. The direction of the arrow indicates the location of the gene. An arrow pointing down indicates the gene or operon is in the plus or sense strand and the arrow pointing up indicates the gene or operon is in the minus or anti-sense strand. 
was predicted (Table 3). As expected, the cDNA for etrA, shows no significant hybridization signal in EtrA71 mutant (ratio 0.05).

\section{Stress response caused by the etrA deletion}

We detected induction of genes from various categories, which have been associated with stress response i.e., starvation, phage infection and oxidative stress, possibly due to accumulation of nitrogen oxide reactive species. Up-regulated genes (Additional file 1) were dominated by genes grouped in "Other categories". The majority of up-regulated genes were phage-related. For example, 25 genes of the LambdaSo phage (SO2940-2974), a gene encoding a viral capsid protein of the MuSo1 phage (SO0675), and genes of MuSo2 phage (SO2684-2685, SO2687, SO2702) were up-regulated. In contrast, the gene encoding the LambdaSo phage transcriptional regulator of the Cro/CI family (SO2990) was down-regulated (ratio 0.43). Transcriptional changes of most of these genes are likely indirect effects due to the deletion of the etrA gene and only for the LambdaSo phage genes S02957-2962 was an EtrA binding site predicted.

The category "Transport and binding proteins" contains a large number of genes associated with stress response. Up-regulated genes in this group contain genes encoding heavy metal efflux pumps (SO0520, SO4596-4598, SOA0153) and genes for phosphate transport (SO1560, SO1723-1724 including pstB-1 [SO1725], pstB-2 [SO4289] and pstA [SO4290]). There was up-regulation of phoBR (SO1558-59) and phou (SO1726) genes, which regulate the phosphate transporters genes during phosphate starvation [28-32].

Up-regulated genes in response to stress conditions i.e., starvation, phage infection, oxidative stress, include a stringent starvation protein encoded by the $\operatorname{ssp} A B$ genes (SO0611-0612) [33], and a phage shock protein operon pspABC (SO1807-1809)[34]. Other up-regulated stress-related genes were the RNA polymerase sigma-70 factor rpoD (SO1284)[32,35], a GTP-binding protein that regulates the TCA cycle and responds to starvation (era [SO1349])[36], and a DNA repair protein (recO [SO1350])[37].

\section{Discussion}

The results of this study demonstrate that EtrA positively regulates dissimilatory nitrate, fumarate and DMSO reduction pathways in S. oneidensis MR-1. The generation of etrA knockout mutant EtrA7-1 in the wild type strain MR-1 background eliminated any possible secondary effects on the phenotype, such as the electron transfer perturbation suspected with the rifampicin resistant DSP10 strain [6]. Similar to other etrA mutants of strain MR-1, EtrA7-1 retained its ability to reduce nitrate $[6,7,16]$; however, our results show that the anaerobic growth of the mutant was significantly impaired compared to the wild type when nitrate was the only electron acceptor. Likewise, the etrA deletion mutant lost its ability to reduce fumarate and DMSO with both lactate and pyruvate as electron donor. Regulation of DMSO reduction by EtrA in strain MR-1 was suggested previously [6] however this study provides physiological evidence that confirm its role. The ability of the EtrA7-1 mutant to reduce TMAO and thiosulfate also decreased; however the reduction of $\mathrm{Fe}(\mathrm{III})$ citrate, $\mathrm{Mn}$ (IV) and sulfite was not affected by the deletion. No differences in growth performance between the wild type and the mutant were observed under aerobic conditions (data not shown).

The transcriptome analysis provides a genome-wide expression profile of $S$. oneidensis MR-1 instead of the partial genome array that was previously evaluated (691 ORFs [6] vs 4,648 genes in this study). We observed in 612 (13\%) differentially expressed genes represented though some are likely due to differences in growth rate between the mutant strain and the wild type strain. Nonetheless, the expression patterns of genes are consistent with the physiological data and with the transcription data reported for Fnr in E. coli $[11,12,20]$ and with the more limited data by Beliaev et al. [6]. Genes involved in nitrate reduction (napDAHGB, $n r f A$, and $h c p$ ) were significantly down-regulated by the etrA deletion as well as those encoding the fumarate reduction ( $\left.f r d A B, f_{c c} A\right)$ and all the genes encoding for the DMSO reductases $(d m s A B)$. All of these genes have been considered candidates for EtrA regulation in previous studies; however, results were not conclusive $[5-7,16]$. Sequence analysis of the regulatory regions of the differentially expressed genes, indicated possible EtrA recognition sites for most genes in the "Energy metabolism" category, some of which i.e. napDAHGB, nrfA, frdAB and $d m s A B$, confirms previous results [6] and further suggests that regulation of these genes is via direct interaction of EtrA with their promoters. Putative recognition sites for EtrA were also identified for the two $n q r$ gene clusters, which had not been identified previously. Also, the regulatory regions for $f d h$ gene clusters were evaluated and an EtrA binding site was recognized for only $f d h A-1$. The $f d h-2$ cluster does not possess an EtrA binding site, suggesting a different regulatory system.

Our data indicate that EtrA is a global regulator acting in cooperation with other regulatory proteins to control anaerobic metabolic processes in strain MR-1 $[6,7,16]$, therefore, the expression of these genes cannot be expected to be under an "all or none" regulatory mechanism. Rather, these global regulators respond to multiple stimuli (e.g., oxygen levels, substrates) and finetune regulation via transcriptional control and interactions between regulatory proteins. Studies in S. oneidensis and in other Shewanella species that indicate the 
combined action of transcriptional regulators for the anaerobic metabolism in this organism [4,17-19]. For example, recent studies showed that CRP, EtrA and the product of the cya genes act as expression regulators of several anaerobic respiratory systems, including nitrate reduction in S. oneidensis MR-1 and Shewanella sp. strain ANA-3 [4,17-19]. In E. coli, Fnr and NarP positively regulate the nap and $n r f$ genes $[12,20,38,39]$. MR1 possesses the genes for a homolog of the two-component regulatory system in E. coli NarQ/NarP (SO39813982). The presence of alternate regulators that partially fulfill the function of EtrA can explain why nitrate reduction even though impaired, still occurred in the EtrA7-1 knockout mutant.

Down-regulation of genes for lactate transport was also observed. Since lactate was the source of reducing equivalents and carbon, a lack of electron donor and carbon may have contributed to the impaired growth of the EtrA7-1 mutant. Induction of transport proteins for carbon sources and electron acceptors has also been credited to Fnr in E. coli $[12,20]$, and a putative EtrA binding site was predicted for the gene encoding a lactate permease (SO0827) in MR-1.

Impaired growth of EtrA7-1 could also be due to stress factors caused or enhanced by the deletion (e.g. accumulation of nitrogen oxide reactive species and starvation). The expression of phage-related genes induced in response to irradiation in strain MR-1 has been reported [40]. Up-regulation of the genes involved in activation of the strain MR-1 prophages LambdaSo, MuSo1 and MuSo2 in the EtrA7-1 mutant was observed, suggesting phage activity. Induction of bacterial genes (e.g., nusAG) required to stabilize the Lambda protein antitermination complex in E. coli was also shown $[41,42]$. Conversely, there is repression of the LambdaSo transcription regulator Cro/CI family, which represses the transcription of the Lambda genes in E. coli [43]. Also, the induction of genes associated with starvation, i.e., a condition that could activate the lytic cycle of prophages [43], was confirmed in the expression analysis.

\section{Conclusion}

The involvement of several regulatory controls has complicated the interpretation of gene expression patterns and functions in Shewanella spp. Results from the above etrA deletion mutant studies suggest a global regulatory role for EtrA, but one which works in conjunction with other regulators to fine-tune the expression of key genes in anaerobic metabolic pathways in S. oneidensis strain MR-1. Besides confirming and clarifying previous reports on Fnr regulation, we also provide experimental evidence for a positive regulatory role of EtrA in the DMSO reduction pathway of strain MR-1. Furthermore, our whole-genome transcriptional profile shows the effects of EtrA on the expression of genes not previously evaluated (e.g. $n q r, f d h-1$, phage- and stress-related genes), and differences in the expression pattern of genes previously analyzed (e.g. $c y d A B$ and $s d h C)[6,12]$. These observations are consistent with results obtained by Gralnick et al. [4] suggesting a distinctive regulatory system, although very similar to Fnr in E. coli. A stringent sequence analysis of the regulatory region of the genes affected by the mutation suggest direct interaction of EtrA to those in the "Energy metabolism" category, while stress- and phage-related genes are up-regulated indirectly as a consequence of a secondary perturbation. This and previous work taken together suggest that this regulator is more properly termed Fnr.

\section{Methods}

\section{Bacterial strains and culture conditions}

The bacterial strains, plasmids, primers and, probes used in this study are described in Table 4. S. oneidensis strain MR-1 and its mutant strains were grown in HEPES medium as described [44]. The medium was supplemented with $20 \mathrm{mM}$ lactate and $\mathrm{KNO}_{3}$ was added as electron acceptor in concentrations specified below. Oxygen was removed from the medium by boiling and purging with helium [45]. Cultures of E. coli strain $\beta 2155$ (auxotroph of diaminopimelic acid [DAP]) were grown in LuriaBertani (LB) medium supplemented with $100 \mu \mathrm{g} / \mathrm{ml}$ of DAP at $37^{\circ} \mathrm{C}$. S. oneidensis strain MR-1 was cultivated in aerobic $\mathrm{LB}$ medium at $30^{\circ} \mathrm{C}$ during the mutagenesis process. Antibiotics used for the selection of MR-1 transformants were added in the following concentrations: 25 $\mu \mathrm{g} / \mathrm{ml}$ of kanamycin, $7.5 \mu \mathrm{g} / \mathrm{ml}$ of gentamycin, and 10 $\mu \mathrm{g} / \mathrm{ml}$ of tetracycline. Vessels that received no inoculum or no $\mathrm{KNO}_{3}$ served as negative controls.

\section{Construction of a chromosomal $\triangle$ etrA::IoxP allele}

PCR primers were designed with Vector $\mathrm{NTI}^{\circledR}$ software (InforMax, Inc., Frederick, MD) and synthesized at Integrated DNA Technologies (http://www.idtdna.com).

A deletion mutant of the etrA gene (SO2356) was constructed by allelic replacement as described [44]. Primers etrAN Rev (SacI) and etrAN Fwd (SacII) generated a $520 \mathrm{bp}$ fragment containing about two-thirds of the upstream SO2357 gene, the SO2357-etrA intergenic region, and the first four base pairs of the 753-bp etrA gene (Table 4). Primers etrAC Rev (NdeII) and etrAC Fwd (EcoRI) generated a 526 bp fragment containing the last five base pairs of the etrA gene, the etrASO2355 intergenic region and about half of the downstream SO2355 gene (Table 4). The resulting 'SO2357etrA'-loxP-kan-loxP-'etrA-SO2355' assembly was cloned into the conditionally-replicating plasmid pKNOCK-Gm (Table 4), which encodes resistance to gentamycin, to 
generate plasmid pCCG02. S. oneidensis MR-1 $\mathrm{Km}^{\mathrm{r}} \mathrm{Gm}^{\mathrm{s}}$ colonies were screened by PCR using primers etrAScreenout Fwd and etrAScreenout Rev (Table 4) to identify recombinants in which the etrA gene was replaced by the loxP-kan-loxP cassette.

The kan gene was subsequently removed from the mutant MR-1 genome by Cre recombination $[44,46]$. PCR and DNA sequence analyses confirmed the presence of the chromosomal $\Delta \operatorname{etr} A:: \operatorname{lox} P$ allele. DNA sequencing was performed at the Genomics Technical Support Facility at Michigan State University.

\section{$\triangle e t r A:: / o x P$ mutant complementation}

Plasmid pCM62 (Table 4) was used as the vector for the expression of the etrA gene in a $\triangle \operatorname{etr} A:$ :loxP mutant (strain EtrA7-1). The etrA gene (SO2356) was PCR amplified from $S$. oneidensis MR-1 genomic DNA using the etrAcomp Fwd (BamHI) and etrAcomp Rev (EcoRI) (Table 4). The amplicon was double digested with $B a m \mathrm{HI}$ and EcoRI and ligated to the multiple cloning site in pCM62. This construct (pCCG03) was transformed into EtrA7-1 by conjugation from E. coli $\beta 2155$. Ligation, electroporation into E. coli $\beta 2155$, and conjugation in strain EtrA7-1 were performed as described [44]. Plasmid pCM62 was also transformed into EtrA7-1 via conjugation from E. coli $\beta 2155$ and used as a control for any plasmid effects. Transformants were selected by streaking on LB plates with tetracycline. EtrA7-1 Tc ${ }^{r}$ colonies were diagnosed by PCR using the etrAcomp primers (Table 4) and subsequently sequenced to verify the deletion of the etrA gene.

\section{Phenotypic characterization of the $\triangle$ etrA::IoxP mutant} Cultures of the wild type, EtrA7-1, EtrA7-1 complement and EtrA7-1 harboring pCM62 were grown anaerobically with $3 \mathrm{mM} \mathrm{KNO}$ in HEPES medium. Growth was monitored periodically by OD measurements at $600 \mathrm{~nm}$. Samples $(2 \mathrm{~mL})$ were periodically withdrawn for analysis of nitrate, nitrite and ammonium concentrations as described [44,47].

Cultures of the wild type and EtrA7-1 were also cultivated anaerobically with ferric citrate $(10 \mathrm{mM})$, fumarate $(10 \mathrm{mM})$, disodium thiosulfate $(10 \mathrm{mM})$, trimethylamine $\mathrm{N}$-oxide (TMAO; $10 \mathrm{mM})$, manganese dioxide $(1 \mathrm{mM}$, nominal concentration), dimethyl sulfoxide (DMSO; 2 and $10 \mathrm{mM})$ and disodium sulfite $(1 \mathrm{mM})$, as electron acceptors. The ferric citrate and the manganese dioxide were prepared as described [48]. Evidence of growth via reduction of TMAO, thiosulfate and fumarate was determined by $\mathrm{OD}_{600}$ measurements. Fe(III) reduction was determined by the ferrozine assay following $\mathrm{HCl}$ extraction $[49,50]$. $\mathrm{Mn}(\mathrm{IV})$ reduction was assayed colorimetrically [48]. Cultures supplied with DMSO as the terminal electron acceptor were analyzed by high- performance liquid chromatography (HPLC) for lactate consumption and acetate formation [51]. Sulfite consumption was measured using a DX-100 ion chromatograph (Dionex Corp., Sunnyvale, CA) equipped with an IonPac AS14A Column.

To determine the effects of lactate on the reduction of DMSO, nitrate and fumarate, cultures of the wild type and the EtrA7-1 mutant strain were grown anaerobically with $20 \mathrm{mM}$ sodium pyruvate as the electron donor and dimethyl sulfoxide (DMSO; $1 \mathrm{mM})$, fumarate $(10 \mathrm{mM})$ or nitrate $(2 \mathrm{mM})$ as electron acceptors. DMSO and fumarate reduction were monitored as mentioned above. Nitrate reduction was measured using a Dionex ICS-3000 ion chromatograph (Dionex Corp., Sunnyvale, CA) equipped with an IonPac AS14 Column.

\section{Resting cell assays}

Cells of the wild type strain MR-1 and the EtrA7-1 mutant were grown aerobically in HEPES medium with $20 \mathrm{mM}$ lactate as the electron donor to $\mathrm{OD}_{600}=0.2$. Cells were harvested by centrifuging for $10 \mathrm{~min}$ at 3,000 $g$, washed twice with $50 \mathrm{mM}$ saline phosphate buffer (pH 7.0) [52,53], and resuspended in the same buffer to an $\mathrm{OD}_{600}=1.0$ under anoxic conditions. The cells were incubated with $5 \mathrm{mM} \mathrm{KNO}_{3}$, and after $0,1,2,4,8$ and $24 \mathrm{~h}$ were removed by centrifugation and three $1-\mathrm{mL}$ replicate samples of the supernatant were assayed to determine nitrate and nitrite reduction rates. Assays with autoclaved wild type cells served as negative controls. Nitrate, nitrite and ammonium concentrations were determined as described [44].

\section{Total RNA preparations}

Total RNA was extracted from triplicate cultures of strains MR-1 and EtrA7-1 grown with $2 \mathrm{mM}$ nitrate as the sole electron acceptor. The RNA was extracted with RNAwiz Solution following the instructions of the manufacturer (Ambion, Inc., Austin, TX). RNA samples were treated with RNase-free DNaseI (Roche Pharmaceuticals, Basel, Switzerland) and purified by phenol:chloroform (1:1) and chloroform extractions [54], and stored in ethanol at $-80^{\circ} \mathrm{C}$ until use. Quality of the RNA was verified using the RNA 6000 Pico LabChip kit and the 2100 Bioanalyzer (Agilent Technologies, Inc., Santa Clara, CA).

\section{Global expression analyses}

A S. oneidensis strain MR-1 whole genome microarrays [55] were provided by Liyou Wu and Jizhong Zhou (Oak Ridge National Laboratory, Oak Ridge, TN). cDNA preparation and labeling were performed as described [56] using a 2:3 ratio of 5-(3-aminoallyl)-dUTP and dTTP. Hybridization and post-hybridization washes were done as described [57]. Three biological replicates per treatment were used for the hybridization of six 
Table 4 Bacterial strains, plasmids, primers and oligonucleotides used in this study

\begin{tabular}{|c|c|c|}
\hline Strain/plasmid/primer/Probe & Relevant genotype or sequence ${ }^{\mathrm{a}, \mathrm{b}}$ & Source \\
\hline \multicolumn{3}{|l|}{ Escherichia coli K-12 } \\
\hline$\beta 2155$ & DAP auxotroph & {$[61]$} \\
\hline \multicolumn{3}{|l|}{ Shewanella oneidensis } \\
\hline MR-1 (ATCC $\left.700550^{\top}\right)$ & wild type & {$[62]$} \\
\hline EtrA7-1 & As MR-1 but $\triangle$ etrA:./oxP & This study \\
\hline EtrA7-1 complement & $\begin{array}{l}\text { EtrA7-1 complemented with the etrA gene (SO2356) cloned into } \\
\text { pCM62 }\end{array}$ & This study \\
\hline EtrA7-1 with pCM62 & EtrA7-1 harboring the pCM62 as a negative control for complementation & This study \\
\hline \multicolumn{3}{|l|}{ Plasmids } \\
\hline pCM62 & Tc'; traJ' trfa oriT oriV & {$[63]$} \\
\hline pCM157 & Tc'; trfA oriT oriV ColE1 ori; lacZp-cre & {$[46]$} \\
\hline pCM184 & $A p^{r} T C^{r} ;$ loxP-kan-loxP & {$[46]$} \\
\hline pKNOCK-Gm & $\mathrm{Gm}^{\mathrm{r}} ;$ ori $_{\mathrm{R} 6 \mathrm{~K}}$ orit $T_{\mathrm{RP} 4}$ & {$[64]$} \\
\hline pCCG02 & As pKNOCK-Gm but etrA'-loxP-kan-loxP-'etrA & This study \\
\hline pCCG03 & As pCM62 but lacZp-etrA & This study \\
\hline \multicolumn{3}{|l|}{ Primers $^{c}$} \\
\hline etrAN Fwd & GCCGCGGTCATGTCGGTTCTCAAGT & \\
\hline etrAN Rev & CGAGCTCCGACAGCTATCTGTTAGTCT & \\
\hline etrAC Fwd & CGAATTCAAATCACCGCTTTAACTTG & \\
\hline etrAC Rev & GCATATGCCAGATAAATCACACCTITT & \\
\hline etrAScreenout & AATTCTTCAGGCATTTGACTCG & \\
\hline \multicolumn{3}{|l|}{ Fwd } \\
\hline etrAScreenout & GGCCGTATCTTGAGTTATACCC & \\
\hline \multicolumn{3}{|l|}{ Rev } \\
\hline etrAcomp Fwd & GGATCCAGGTGTGATTTATCTGGCG & \\
\hline etrAcomp Rev & GAATTCCCGACATGACAATAGAGCAGA & \\
\hline 23SRT Fwd & TAGCGAAATTCCTTGTCGGG & \\
\hline 23SRT Rev & GAGACAGCGTGGCCATCATT & \\
\hline 23Stemp Rev & GTATCAGTTAGCTCAACGCCTC & \\
\hline napART Fwd & AGAAAGCCCTGTTAACCGTGG & \\
\hline napART Rev & TCATCCGCAGCAATGGTGT & \\
\hline napAtemp Rev & GATCGAAGCTACGGTTCTCG & \\
\hline nrfART Fwd & GCCACATGTATGCCGTGACT & \\
\hline nrfART Rev & TITACAGCTCCAGCAAGCCA & \\
\hline nrfAtemp Rev & ACGTTTCATACTCGGGATGC & \\
\hline \multicolumn{3}{|l|}{ Probes } \\
\hline 23SRTProbe & AGTTCCGACCTGCACGAATGGCG & \\
\hline napARTProbe & CTGTATTAAAGGTTACTTCCTGTCGAAAATCATGTACGG & \\
\hline nrfARTProbe & CGTAATACCTTGCGTACTGGCGCGC & \\
\hline
\end{tabular}

${ }^{a}$ The sequence for the primers is written from the 5 'end to the 3 'end.

${ }^{b}$ Primers were designed using putative gene sequences of $S$. oneidensis MR-1.

' For primer sequences, the restriction sites incorporated are underlined. CATATG, Ndel; GAATTC, EcoRl; GAGCTC, Sacl; CCGCGG, Sacll.

microarray slides including technical duplicates (dyeswap). Data analysis was performed using the GeneSpring 6.0 software (Silicon Genetics, Redwood City, CA). The data were normalized per chip and per gene (Lowess Normalization) and the spots with less than $55 \%$ pixel intensity above background plus two standard deviations were eliminated from the analyses [58]. The data were filtered using the Benjamini and Hochberg false discovery rate with $95 \%$ confidence and only those genes with a $>2$-fold change in expression were considered significant.

\section{Microarray data accession number}

The raw microarray intensity data has been deposited in the GenBank Gene Expression Omnibus (GEO) database under the accession number GSE26935. 


\section{Identification of putative EtrA binding sites}

Regulatory motifs were predicted in the intergenic regions of differentially expressed genes using the Gibbs centroid sampler [59]. Intergenic regions were extracted, based on the $S$. oneidensis MR-1 genome annotation, that were at least $50 \mathrm{bp}$ in length and upstream of differentially expressed genes or operons whose change in expression (average \pm one standard deviation) was at least 2.5 -fold. A total of 170 genes met these requirements: 55 had expression levels minus one standard deviation of $\geq 2.5$ (up-regulated genes) and $115 \mathrm{had}$ expression levels plus one standard deviation of $\leq 0.4$ (down-regulated genes). For these genes, 118 upstream intergenic regions were extracted for analysis, after accounting for multiple genes within an operon. The parameters for the Gibbs centroid sampler used on these sequences were the following: up to two motif models were allowed, where each model was specified to be palindromic and 16-24 bases long, a maximum of three sites per intergenic was allowed, a position-specific background model [60] was employed, and centroid sampling was performed with 1000 burn-in iterations, 5000 sampling iterations and 10 random seeds. The results from four independent runs were compared, and the subset of 47 intergenic regions extracted that contained a predicted regulatory motif in at least one of those runs. These 47 intergenic sequences were analyzed with the Gibbs centroid sampler, using the same parameters as above, except that only one motif model was specified. Additional binding sites were detected using dscan (http://ccmbweb.ccv.brown.edu/cgi-bin/dscan.pl) to search the set of promoters for all the genes that exhibited $\geq 2$-fold change in expression (Additional file 1 ). This set included a total of 424 intergenic regions.

\section{Additional material}

Additional file 1: Supplemental Table SI1. Genes differentially expressed in anaerobic cultures of MR-1 and Etra7-1 at different concentrations of KNO3. Complete list of genes differentially expressed including relative expression, standard deviation, "TIGR role" and predicted EtrA binding sites.

Additional file 2: Figure SI1. Distribution of differentially expressed genes (> 2-fold change) grouped in 19 functional categories in anaerobic cultures of EtrA7-1 compared to the wild type grown on lactate and nitrate. The total of genes down-regulated is 323 and the up-regulated is 289. Each bar represents the number of up-regulated (white) and down-regulated (black) genes for each functional category. Abreviations: [PS], Protein synthesis; [DM], DNA Metabolism; [RF], Regulatory Function; [CIM], Central Intermediary Metabolism; [EM], Energy Metabolism; [OC], Other Categories; [UF], Unknown Function; [TBP], Transport Binding Proteins; [PF], Protein Fate; [HP], Hypothetical Protein; [AAB], Amino Acid Biosynthesis; [FAPM], Fatty Acid and Phospholipid Metabolism; [DRF], Disrupted Reading Frame; [CP], Cellular Processes; [BCPGC], Biosynthesis of Cofactors, Prosthetic Groups, and Carriers; [CE], Cell Envelope; [ST], Signal Transduction; [T], Transcription; and [PPNN], Purines, Pyrimidines, Nucleosides and Nucleotides.
Additional file 3: Figure SI2. Sequence logo (http://weblogo. berkeley.edu/logo.cgi) of the identified EtrA binding site motif for S. oneidensis MR-1. The logo represents the palindromic model of the aligned sites, showing the relative frequency of each base at each position of the motif. The $Y$-axis indicates the information content measured in bits. All of the predicted sites that contribute to the model are in Table SI1 in the supplementary materials.

\section{Acknowledgements}

We thank Xiaoyun Qiu for advice on the DNA microarray work, Valley Stewart and Joel Klappenbach for advice and discussion. We thank Benjamin K. Amos, Jed Costanza, Qingzhong Wu and Sara H. Thomas for technical assistance in the phenotypic characterization of the EtrA7-1 strain. We also acknowledge members of the Shewanella Federation for helpful discussions. This study was supported by Department of Energy grants DE-FG0202 ER63342 from the Genomics Program, Office of Biological and Environmental Research (awarded to JMT), DE-FG02-04ER63718.25 from the Environmental Remediation Science Division, Biological and Environmental Research (awarded to FEL) and DE-FG02-04ER63942 from the Genomes to Life Program, Office of Biological and Environmental Research (awarded to LAM). Contributions by MFR and LAM were performed at Pacific Northwest National Laboratory, which is operated by Battelle for the United States Department of Energy under Contract DE-AC05-76RL01830.

\section{Author details}

${ }^{1}$ Center for Microbial Ecology, Michigan State University, East Lansing, Michigan 48824-1325, USA. ²Department of Crop and Soil Sciences, Michigan State University, East Lansing, Michigan 48824-1325, USA. ${ }^{3}$ Department of Microbiology and Molecular Genetics, Michigan State University, East Lansing, Michigan 48824-1325, USA. ${ }^{4}$ Department of Biology, University of Texas at Arlington, Arlington, Texas 76019, USA. ${ }^{5}$ Department of Microbiology, University of Minnesota, St. Paul, MN 55108, USA. ${ }^{6}$ Pacific Northwest National Laboratory, Richland, Washington 99352, USA.

${ }^{7}$ Department of Microbiology, University of Tennessee, Knoxville, MN 37996, USA. ${ }^{8}$ Department of Civil and Environmental Engineering, University of Tennessee, Knoxville, MN 37996, USA. 'Oak Ridge National Laboratory, Oak Ridge, TN 37831, USA. ${ }^{10} \mathrm{Georgia}$ Institute of Technology, School of Civil and Environmental Engineering, 311 Ferst Drive, Atlanta, GA 30332-0512, USA.

${ }^{11}$ Division of Earth and Ecosystem Sciences, Desert Research Institute, Reno, NV 89512, USA.

\section{Authors' contributions}

All authors contributed in the organization and design of experiments as well as data interpretation and manuscript preparation. CCG, FEL, and JMT wrote the paper. CCG designed and carried out the majority of the experimental work including mutant construction, cDNA microarray experiments and analysis, and growth studies. AEM, MFR and LAM contributed in experimental design and CDNA microarray data analysis and interpretation. JLMR performed resting cell assays. JAG replicated DMSO physiological experiments. LAM performed EtrA binding site identification. MFR provided updated genome sequence annotation. FEL provided laboratory equipment, materials, and funding and supervision for the phenotypic characterization work. JMT supervised experimental work. All authors read and approved the final version of the manuscript.

Received: 14 July 2010 Accepted: 30 March 2011

Published: 30 March 2011

\section{References}

1. Holden M, Bentley S, Sebaihia M, Thompson N, Cerdeño-Tárraga A, Parkhill J: The magnificent seven. Trends Microbiol 2003, 11:12-14.22.

2. Tiedje JM: Shewanella-the environmentally versatile genome. Nat Biotechnol 2002, 20:1093-1094.

3. Heidelberg JF, Paulsen IT, Nelson KE, Gaidos EJ, Nelson WC, Read TD, Eisen JA, Seshadri R, Ward N, Methe B, Clayton RA, Meyer T, Tsapin A, Scott J, Beanan M, Brinkac L, Daugherty S, DeBoy RT, Dodson RJ, Durkin , Haft DH, Kolonay JF, Madupu R, Peterson JD, Umayam LA, White O, Wolf AM, Vamathevan J, Weidman J, Impraim M, Lee K, Berry K, Lee C, 
Mueller J, Khouri H, Gill J, Utterback TR, McDonald LA, Feldblyum TV, Smith HO, Venter JC, Nealson KH, Fraser CM: Genome sequence of the dissimilatory metal ion-reducing bacterium Shewanella oneidensis. Nat Biotechnol 2002, 20:1118-1123.

4. Gralnick JA, Brown CT, Newman DK: Anaerobic regulation by an atypical Arc system in Shewanella oneidensis. Mol Microbiol 2005, 56:1347-1357.

5. Saffarini DA, Schultz R, Beliaev A: Involvement of cyclic AMP (cAMP) and CAMP receptor protein in anaerobic respiration of Shewanella oneidensis. J Bacteriol 2003, 185:3668-3671.

6. Beliaev AS, Thompson DK, Fields MW, Wu L, Lies DP, Nealson KH, Zhou J: Microarray transcription profiling of a Shewanella oneidensis etrA mutant. J Bacteriol 2002, 184:4612-4616.

7. Maier TM, Myers CR: Isolation and characterization of a Shewanella putrefaciens MR-1 electron transport regulator etrA mutant: reassessment of the role of EtrA. J Bacteriol 2001, 183:4918-4926.

8. Darwin AJ, Ziegelhoffer EC, Kiley PJ, Stewart V: Fnr, NarP, and NarL regulation of $E$. coli $\mathrm{K}-12$ napF (periplasmic nitrate reductase) operon transcription in vitro. J Bacteriol 1998, 180:4192-4198.

9. Darwin AJ, Stewart V: Nitrate and nitrite regulation of the Fnr-dependent aeg-46.5 promoter of $E$. coli $\mathrm{K}-12$ is mediated by competition between homologous response regulators (NarL and NarP) for a common DNAbinding site. J Mol Biol 1997, 251:15-29.

10. Choe M, Reznikoff WS: Anaerobically expressed Escherichia coli genes identified by operon fusion techniques. J Bacteriol 1991, 173:6139-6146.

11. Shalel-Levanon S, San KY, Bennett GN: Effect of ArcA and FNR on the expression of genes related to the oxygen regulation and the glycolysis pathway in Escherichia coli under microaerobic growth conditions. Metab Eng 2005, 7:445-456.

12. Kang Y, Weber KD, Qiu Y, Kiley PJ, Blattner FR: Genome-wide expression analysis indicates that FNR of Escherichia coli K-12 regulates a large number of genes of unknown function. J Bacteriol 2005, 187:1135-1160.

13. Crack J, Green J, Thomson AJ: Mechanism of oxygen sensing by the bacterial transcription factor fumarate-nitrate reduction (FNR). J Biol Chem 2004, 279:9278-9286.

14. Outten FW: Iron-sulfur clusters as oxygen-responsive molecular switches. Nat Chem Biol 2007, 3:206-207.

15. Moore $L$, Mettert EL, Kiley PJ: Regulation of FNR dimerization by subunit charge repulsion. J Biol Chem 2006, 281:33268-33275.

16. Saffarini DA, Nealson $\mathrm{KH}$ : Sequence and genetic characterization of etrA, an fnr analog that regulates anaerobic respiration in Shewanella putrefaciens MR-1. J Bacteriol 1993, 175:7938-7944.

17. Charania MA, Brockman KL, Zhang Y, Banerjee A, Pinchuk GE, Fredrickson JK, Beliaev AS, Saffarini DA: Involvement of a membranebound class III adenylate cyclase in regulation of anaerobic respiration in Shewanella oneidensis MR-1. J Bacteriol 2009, 191:4298-4306.

18. Murphy JN, Saltikov CW: The ArsR repressor mediates arsenite-dependent regulation of arsenate respiration and detoxification operons of Shewanella sp. Strain ANA-3. J Bacteriol 2009, 191:6722-6731.

19. Murphy JN, Durbin KJ, Saltikov CW: Functional roles of $\operatorname{arcA}$, etrA, cyclic AMP (cAMP)-cAMP receptor protein, and cya in the arsenate respiration pathway in Shewanella sp. strain ANA-3. J Bacteriol 2009, 191:1035-1043.

20. Overton TW, Griffiths L, Patel MD, Hobman JL, Penn CW, Cole JA, Constantinidou C: Microarray analysis of gene regulation by oxygen, nitrate, nitrite, FNR, NarL and NarP during anaerobic growth of Escherichia coli: new insights into microbial physiology. Biochem Soc $T$ 2006, 34:104-107.

21. Myers CR, Myers JM: Role of the tetraheme cytochrome CymA in anaerobic electron transport in cells of Shewanella putrefaciens MR-1 with normal levels of menaquinone. J Bacterio/ 2000, 182:67-75.

22. Fredrickson JK, Romine MF: Genome-assisted analysis of dissimilatory metal-reducing bacteria. Curr Opin Biotechnol 2005, 16:269-274.

23. Hayashi M, Hirai K, Unemoto T: Sequencing and the alignment of structural genes in the nqr operon encoding the $\mathrm{Na}(+)$-translocating NADH-quinone reductase from Vibrio alginolyticus.. FEBS Lett 1995, 363:75-77

24. Filenko NA, Browning DF, Cole JA: Transcriptional regulation of a hybrid cluster (prismane) protein. Biochem Soc Trans 2005, 33:195-197.

25. Cabello P, Pino C, Olmo-Mira MF, Castillo F, Roldán MD, Moreno-Vivián C: Hydroxylamine assimilation by Rhodobacter capsulatus E1F1. requirement of the $h c p$ gene (hybrid cluster protein) located in the nitrate assimilation nas gene region for hydroxylamine reduction. $J$ Biol Chem 2004, 279:45485-45494

26. Wolfe MT, Heo J, Garavelli JS, Ludden PW: Hydroxylamine reductase activity of the hybrid cluster protein from Escherichia coli. J Bacteriol 2002, 184:5898-5902.

27. van den Berg WA, Hagen WR, van Dongen WM: The hybrid-cluster protein ('prismane protein') from Escherichia coli. Characterization of the hybridcluster protein, redox properties of the $[2 \mathrm{Fe}-2 \mathrm{~S}]$ and $[4 \mathrm{Fe}-2 \mathrm{~S}-2 \mathrm{O}]$ clusters and identification of an associated NADH oxidoreductase containing FAD and [2Fe-2S]. Eur J Biochem 2000, 267:666-676.

28. White AK, Metcalf WW: The $h t x$ and ptx operons of Pseudomonas stutzeri WM88 are new members of the pho regulon. J Bacteriol 2004, 186:5876-5882

29. White AK, Metcalf WW: Isolation and biochemical characterization of hypophosphite/2-oxoglutarate dioxygenase. A novel phosphorusoxidizing enzyme from Pseudomonas stutzeri WM88. J Biol Chem 2002, 277:38262-38271.

30. Jiang ZD, Greenberg D, Natarro JP, Stephen R, DuPont HL: Rate of occurrence and pathogenic effect of enteroaggregative Escherichia coli virulence factors in international travelers. J Clin Microbiol 2002, 40:4185-4190.

31. Jiang W, Metcalf WW, Lee KS, Wanner BL: Molecular cloning, mapping, and regulation of Pho regulon genes for phosphonate breakdown by the phosphonatase pathway of Salmonella typhimurium LT2. J Bacteriol 1995, 177:6411-6421.

32. Kim SK, Makino K, Amemura M, Nakata A, Shinagawa H: Mutational analysis of the role of the first helix region 4.2 of the sigma 70 subunit of Escherichia coli RNA polymerase in transcriptional activation by activator protein PhoB. Mol Gen Genet 1995, 248:1-8.

33. Hansen AM, Gu Y, Li M, Andrykovitch M, Waugh DS, Jin DJ, Ji X: Structural basis for the function of stringent starvation protein a as a transcription factor. J Biol Chem 2005, 280:17380-17391.

34. Jovanovic G, Weiner L, Model P: Identification, nucleotide sequence, and characterization of PspF, the transcriptional activator of the Escherichia coli stress-induced psp operon. J Bacteriol 1996, 178:1936-1945.

35. Klancnik A, Bottledoorn N, Herman L, Mozina SS: Survival and stress induced expression of groEL and rpoD of Campylobacter jejuni from different growth phases. Int J Food Microbiol 2006, 112:200-207.

36. Pillutla RC, Ahnn J, Inouye M: Deletion of the putative effector region of Era, an essential GTP-binding protein in Escherichia coli, causes a dominant-negative phenotype. FEMS Microbiol Lett 1996, 143:47-55.

37. Luisi-DeLuca C, Kolodner R: Purification and characterization of the Escherichia coli RecO protein. J Mol Biol 1994, 236:124-138.

38. Cotter PA, Gunsalus RP: Oxygen, nitrate and molybdenum regulation of dmsABC genes expression in Escherichia coli.. J Bacteriol 1989, 171:3817-3823.

39. Stewart V, Bledsoe PJ, Williams SB: Dual overlapping promoters control napF (periplasmic nitrate reductase) operon expression in Escherichia coli K-12. J Bacteriol 2003, 185:5862-5870.

40. Qiu X, Sundin GW, Wu L, Zhou J, Tiedje JM: Comparative analysis of differentially expressed genes in Shewanella oneidensis MR-1 following exposure to UVC, UVB, and UVA radiation. J Bacterio/ 2005, 187:3556-3564.

41. Bonin I, Muhlberger R, Bourenkov GP, Huber R, Bacher A, Richter G, Wahl WC: Structural basis for the interaction of Escherichia coli NusA with protein $\mathrm{N}$ of phage lambda. Proc Natl Acad Sci USA 2004, 101:13762-13767.

42. Torres M, Balada JM, Zellars M, Squires C, Squires C: In vivo effect of NusB and NusG on rRNA transcription antitermination. J Bacteriol 2004, 186:1304-1310.

43. Voyles BA: The biology of viruses. Mosby-Year Book, Inc., St. Louis, MO; 1993.

44. Cruz-García C, Murray AE, Klappenbach NJA, Stewart V, Tiedje JM: Respiratory Nitrate Ammonification by Shewanella oneidensis MR-1. J Bacteriol 2007, 189:656-662.

45. Balch WE, Wolfe RS: New approach to the cultivation of methanogenic bacteria: 2-mercaptoethanesulfonic acid (HS-CoM)-dependent growth of Methanobacterium ruminantium in a pressureized atmosphere. Appl Environ Microbiol 1976, 32:781-791.

46. Marx CJ, Lidstrom ME: Broad-host-range cre-lox system for antibiotic marker recycling in gram-negative bacteria. Biotechniques 2002, 33:1062-1067. 
47. Nelson DW: Determination of ammonium in $\mathrm{KCl}$ extracts of soils by the salicylate method. Comm Soil Sci Plant Anal 1983, 14:1051-1062.

48. Burlage RS, Atlas R, Stahl D, Gessey G, Sayler G: Techniques in Microbial Ecology. Oxford University Press US, New York, NY; 1988.

49. Lovley DR, Phillips EJP: Novel Mode of Microbial Energy Metabolism: Organic Carbon oxidation Coupled to Dissimilatory Reduction of Iron or Manganese. Appl Environ Microbiol 1988, 54:1472-1480.

50. Lovley DR, Phillips EJP: Availability of Ferric Iron Microbial Reduction in Bottom Sediments of the Freshwater Tidal Potomac River. Appl Environ Microbiol 1986, 52:751-757.

51. He J, Ritalahti RM, Aiello MR, Löffler FE: Complete Detoxification of Vinyl Chloride by an Anaerobic Enrichment Culture and Identification of the Reductively Dechlorinating Population as a Dehalococcoides species. Appl Environ Microbiol 2003, 69:996-1003.

52. Rodrigues JLM, Maltseva OV, Tsoi TV, Helton RR, Quensen JF III, Fukuda M, Tiedje JM: Development of a Rhodococcus recombinant strain for degradation of products from anaerobic dechlorination of PCBs. Environ Sci Technol 2001, 35:663-668.

53. Löfler FE, Champine JE, Ritalahti KM, Sprague SJ, Tiedje JM: Complete reductive dechlorination of 1,2-dichloropropane by anaerobic bacteria. Appl Environ Microbiol 1997, 63:2870-2875.

54. Sambrook J, Russell DW: Molecular Cloning: A Laboratory Manual. Cold Spring Harbor Laboratory Press, Cold Spring Harbor, NY; 2001.

55. Gao H, Wang Y, Liu X, Yan T, Wu L, Alm E, Arkin A, Thompson DK, Zhou J: Global transcriptome analysis of the heat shock response of Shewanella oneidensis. J Bacteriol 2004, 186:7796-7803.

56. Schroeder RG, Peterson LM, Fleischmann RD: Improved quantitation and reproducibility in Mycobacterium tuberculosis DNA microarrays. J Mol Microbiol Biotechnol 2002, 4:123-126.

57. Hedge P, Qi R, Abernathy K, Gay C, Dharap S, Gaspard R, Earlehughes J, Snesrud E, Lee N, Quackenbush J: A concise guide to CDNA microarray analysis. BioTechniques 2000, 29:548-562.

58. Murray AE, Lies D, Li G, Nealson KH, Zhou J, Tiedje JM: DNA/DNA hybridization to microarrays reveals gene-specific differences between closely related microbial genomes. Proc Natl Acad Sci 2001, 98:9853-9858

59. Thompson WA, Newberg LA, Conlan S, McCue L, Lawrence CE: The Gibbs centroid sampler. Nucleic Acids Res 2007, 35:W232-237.

60. Liu JS, Lawrence CE: Bayesian inference on biopolymer models. Bioinformatics 1999, 15:38-52.

61. Demarre G, Guérout AM, Matsumoto-Mashimo C, Rowe-Magnus DA, Marlière P, Mazel D: A new family of mobilizable suicide plasmids based on broad host range R388 plasmid (IncW) and RP4 plasmid (IncPa) conjugative machineries and their cognate Escherichia coli host strains. Res Microbiol 2005, 156:245-255

62. Myers $\mathrm{CR}$, Nealson $\mathrm{KH}$ : Bacterial manganese reduction and growth with manganese oxide as the sole electron acceptor. Science 1988, 240:1319-1321.

63. Marx CJ, Chistoserdova L: Development of versatile broad-host-range vectors for use in methylotrophs and other gram-negative bacteria. Microbiology 2001, 147:2065-2075.

64. Alexeyev MF: The pKNOCK series of broad-host-range mobilizable suicide vectors for gene knockout and targeted DNA insertion into the chromosome of gram-negative bacteria. BioTechniques 1999, 26:824-828.

\section{doi:10.1186/1471-2180-11-64}

Cite this article as: Cruz-García et al:: Fnr (EtrA) acts as a fine-tuning regulator of anaerobic metabolism in Shewanella oneidensis MR-1. BMC Microbiology 2011 11:64.

\section{Submit your next manuscript to BioMed Central and take full advantage of:}

- Convenient online submission

- Thorough peer review

- No space constraints or color figure charges

- Immediate publication on acceptance

- Inclusion in PubMed, CAS, Scopus and Google Scholar

- Research which is freely available for redistribution

Submit your manuscript at www.biomedcentral.com/submit
C Biomed Central 